\title{
Meropenem: continuous or extended infusion?
}

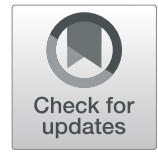

Frédéric Frippiat ${ }^{1,2^{*}}$, Christelle Vercheval ${ }^{3}$ and Nathalie Layios ${ }^{4}$

\section{To the Editor}

We read with interest the article by Benitez-Cano and colleagues about intrapulmonary concentrations of meropenem administered by continuous infusion (CI) in critically ill patients with nosocomial pneumonia and would like to make some comments [1].

Firstly, the pharmacokinetic/pharmacodynamic (PK/PD) target was a free epithelial lining fluid (ELF) concentration of $50 \%$ of time above MIC ( $50 \% f \mathrm{~T}>\mathrm{MIC})$. In our opinion, a PK/PD target of $100 \% f \mathrm{~T}>\mathrm{MIC}$ was more suitable, since the study was performed under CI. Indeed, despite the fact that the authors stated that "a precise estimate of the concentration-time profile in ELF was not possible because all ELF samples were obtained at the same time," CI of $\beta$-lactams allows reasonably a $24 / 24$ stable concentration both in plasma and ELF, as illustrated in the figures 2 and 6 for the plasma and ELF, respectively [1], and as shown in other studies [2, 3].

Secondly, considering a target of $50 \% f \mathrm{~T}>\mathrm{MIC}$, similar results were obtained with both extended infusion (EI) over $4 \mathrm{~h}$ and $\mathrm{CI}$ (i.e., MIC up to 1 and up to $2 \mathrm{mg} / \mathrm{L}$ for both modes of infusion with $1 \mathrm{~g} / 8 \mathrm{~h}$ and $2 \mathrm{~g} / 8 \mathrm{~h}$, respectively), which are close to our results with EI over $3 \mathrm{~h}$ (i.e., MICS up to 0.5 and up to $1 \mathrm{mg} / \mathrm{L}$ with $1 \mathrm{~g} / 8 \mathrm{~h}$ and $2 \mathrm{~g} / 8 \mathrm{~h}$, respectively) [4]. Thus, CI does not offer significant PK/ PD advantages over EI for meropenem. On a practical point of view, CI of meropenem needs a dedicated intravenous line access (which is not always obvious in critically ill patients) and frequent infusion syringes changes (every $5-8 \mathrm{~h}$ ) due to stability issues, particularly at temperatures $\geq 25^{\circ} \mathrm{C}[5]$.

\footnotetext{
* Correspondence: f.frippiat@chuliege.be

${ }^{1}$ Division of Infectious Diseases, Department of Internal Medicine, University Hospital of Liège, Liège, Belgium

${ }^{2}$ Service de Maladies Infectieuses, CHU de Liège, Avenue de l'hôpital, 1 - B35, Sart Tilman, 4000 Liège, Belgium

Full list of author information is available at the end of the article
}

Thirdly, studies performed in critically ill patients with nosocomial pneumonia showed a high interindividual variability in the $\beta$-lactams concentrations in ELF whatever the mode of infusion [1-4]. We agree with BenitezCano et al. that even the highest dosage of meropenem $(2 \mathrm{~g} / 8 \mathrm{~h})$ administered by either CI or EI could not result in an optimal ELF target attainment for a substantial fraction of the population, particularly in patients with augmented renal clearance.

In conclusion, when meropenem is considered as the initial empiric antibiotic therapy for nosocomial pneumonia in critically ill patients, we strongly recommend the dosage of $2 \mathrm{~g} / 8 \mathrm{~h}$ by EI over $3 \mathrm{~h}$ (or by CI if the cartridge is changed every $5-8 \mathrm{~h}$ and the temperature remains below $25^{\circ} \mathrm{C}$ ) to optimize chances for therapeutic concentrations in ELF.

\section{Acknowledgements \\ Not applicable}

Authors' contributions

I declare that all authors contributed equally to the redaction of this manuscript. The authors read and approved the final manuscript.

\section{Funding}

None

Availability of data and materials

Not applicable

Ethics approval and consent to participate

Not applicable

\section{Consent for publication}

Not applicable

\section{Competing interests \\ Not applicable}

\section{Author details}

${ }^{1}$ Division of Infectious Diseases, Department of Internal Medicine, University Hospital of Liège, Liège, Belgium. 'Service de Maladies Infectieuses, CHU de Liège, Avenue de l'hôpital, 1 - B35, Sart Tilman, 4000 Liège, Belgium.

${ }^{3}$ Department of Clinical Pharmacy, University Hospital of Liège, Liège, 
Belgium. ${ }^{4}$ Department of Intensive Care Unit, University Hospital of Liège, Liège, Belgium.

Received: 18 March 2020 Accepted: 8 April 2020

Published online: 05 May 2020

\section{References}

1. Benítez-Cano A, Luque S, Sorlí L, Carazo J, Ramos I, Campillo N, Curull V, Sánchez-Font A, Vilaplana C, Horcajada JP, Adalia R, Bermejo S, Samsó E, Hope W, Grau S. Intrapulmonary concentrations of meropenem administered by continuous infusion in critically ill patients with nosocomial pneumonia: a randomized pharmacokinetic trial. Crit Care. 2020;24:55.

2. Boselli E, Breilh D, Rimmelé T, Guillaume C, Xuereb F, Saux MC, Bouvet L, Chassard D, Allaouchiche B. Alveolar concentrations of piperacillin/ tazobactam administered in continuous infusion to patients with ventilatorassociated pneumonia. Crit Care Med. 2008;36:1500-6.

3. Heffernan AJ, Sime FB, Lipman J, Dhanani J, Andrews K, Ellwood D, Grimwood K, Roberts JA. Intrapulmonary pharmacokinetics of antibiotics used to treat nosocomial pneumonia caused by Gram-negative bacilli: a systematic review. Int J Antimicrob Agents. 2019;53:234-45.

4. Frippiat F, Musuamba FT, Seidel L, Albert A, Denooz R, Charlier C, Van Bambeke F, Wallemacq P, Descy J, Lambermont B, Layios N, Damas P, Moutschen M. Modelled target attainment after meropenem infusion in patients with severe nosocomial pneumonia: the PROMESSE study. J Antimicrob Chemother. 2015;70:207-16.

5. Delattre IK, Briquet C, Wallemacq P, Tulkens PM, Van Bambeke F. Comparative in vitro antimicrobial potency, stability, colouration and dissolution time of generics versus innovator of meropenem in Europe. Int J Antimicrob Agents. 2020;55:105825.

\section{Publisher's Note}

Springer Nature remains neutral with regard to jurisdictional claims in published maps and institutional affiliations. 